Check for updates

The BMJ

rcoombes@bmi.com

Cite this as: BMJ 2022;376:071

http://dx.doi.org/10.1136/bmj.071

Published: 13 January 2022

\title{
Covid-19: This is a gamble and not a plan
}

\section{Rebecca Coombes head of journalism}

The BMJ this week is filled with frontline reports of a health service at breaking point as omicron continues to batter the NHS.

Quality of care has fallen to below-acceptable thresholds for many. So far, at least 24 of England's 137 NHS trusts have declared critical incidents, but there is good reason to believe the effect on care goes far beyond this, and many hospitals are struggling under the radar (doi:10.1136/bmj.o6o). ${ }^{1}$ The BMA warns that a dramatic slowdown in the provision of non-urgent care is causing "untold suffering" to the record nearly six million patients on waiting lists (doi:10.1136/bmj.045). ${ }^{2}$ The army has been called in to help London hospitals (doi:10.1136/bmj.047), ${ }^{3}$ and people are being asked to find lifts to emergency departments because ambulances are taking so long to arrive. As Hugh Alderwick puts it, "Millions of patients and staff are already feeling the negative effects of a healthcare system struggling to cope with the unbearable demands placed on it" (doi:10.1136/bmj.051). 4

NHS staff are exhausted after nearly two years of dealing with the acute stress of the pandemic. Staff absences in hospitals are up by around $40 \%$, and almost half of staff report illness from work related stress (doi:10.1136/bmj.051). 4 There is no reason to think that staff shortages in general practice are any different from acute services, says our GP columnist Helen Salisbury, whose practice has four staff members absent (doi:10.1136/bmj.043). 5 "It's difficult not to be angry," she says, "as this current surge of cases and burden of suffering was predicted and preventable: we had a chance to flatten this wave, and our government chose instead to do nothing."

Meanwhile, the prime minister is gambling that the NHS can "ride out" the pressures of the omicron wave but has not committed to any concrete plans to get the workforce through. Nothing has been learnt from the winter of 2021-22, and no long term plan exists to deal with staff shortages. This prompts the question: how can you take patient safety seriously and yet neglect workforce planning?

Going into the pandemic, the NHS had fewer doctors per capita than similar countries, and the service was 100 ooo short of healthcare staff. Even without a plan to build a future workforce, there are sensible calls to mobilise more staff, such as by asking medical students to volunteer and by shortening self-isolation periods for infected staff, but these calls are not backed by the government (doi:10.1136/bmj.038). ${ }^{6}$ "We should not be in this position two years into a pandemic," says the NHS Confederation's Matthew Taylor.

This latest UK wave is showing signs of peaking in London, and vaccination and better treatments-such as dexamethasone and tocilizumab-continue to reduce the number of critically ill patients (doi:10.1136/bmj.061). ${ }^{7}$ But many parts of the country are still bracing themselves for the peak, leaving staff exposed to the pressures and without even a distant workforce solution for any future surges.

1 Torjesen I. Covid-19: Many hospitals "are not declaring critical incidents" despite severe pressures. BMJ2022;376:060doi: 10.1136/bmj.060.

2 Mahase E. Covid-19: Omicron is "battering" the NHS and causing "untold suffering" for patients, say doctors. BM/2022;376:045. doi: 10.1136/bmj.045 pmid: 35012961

3 lacobucci G. Covid-19: Military drafted in to tackle staffing crisis in London hospitals. BMJ2022;376:047. doi: 10.1136/bmj.047 pmid: 35012973

4 Alderwick $\mathrm{H}$. Is the NHS overwhelmed?BMJ 2022;376:051doi: 10.1136/bmj.051.

5 Salisbury H. Helen Salisbury: Covid-19 and the consequences of letting it rip. BMJ 2022;376:043doi: 10.1136/bmj.043

6 Mahase E. Covid-19: Shorten isolation periods to relieve NHS pressures, say leaders. BMJ2022;376:038. doi: 10.1136/bmj.038 pmid: 34996760

7 Wilkinson E. Covid-19: We have good treatments for omicron, but questions remain, say doctors. BMJ2022;376:061doi: 10.1136/bmj.061

This article is made freely available for personal use in accordance with BMJ's website terms and conditions for the duration of the covid-19 pandemic or unti otherwise determined by BMJ. You may download and print the article for any lawful, non-commercial purpose (including text and data mining) provided that all copyright notices and trade marks are retained. 